Review

\title{
The relevance of team characteristics and team directed strategies in the implementation of nursing innovations: A literature review
}

\author{
Gerda Holleman ${ }^{\mathrm{a}, *}$, Else Poot ${ }^{\mathrm{a}}$, Joke Mintjes-de Groot ${ }^{\mathrm{a}}$, Theo van Achterberg ${ }^{\mathrm{b}}$ \\ a P.O. Box 3135, 3502GC Utrecht, The Netherlands \\ ${ }^{\mathrm{b}}$ IQ Healtcare, 114 Radboud University Nijmegen Medical Centre, P.O. Box 9101, 6500 HB Nijmegen, The Netherlands
}

\section{A R T I C L E I N F O}

Article history:

Received 4 June 2008

Received in revised form 7 January 2009

Accepted 10 January 2009

\section{Keywords:}

Nursing

Implementation of innovation

Teams

Characteristics

Strategies

\begin{abstract}
A B S T R A C T
Background: Implementation of innovations is a complex and intensive procedure in which different strategies can be successful. In nursing, strategies often focus on intrinsic motivation, competencies and attitudes of individual nurses while ignoring the social context. Since nurses often work in teams, identifying relevant team characteristics and successful team directed strategies may contribute to the implementation of innovations. The literature was searched for evidence.

Methods: A literature review was performed including key words related to nursing teams, innovations, team characteristics and team-directed strategies. On-line databases were searched (MEDLINE, CINAHL, PsycINFO, ERIC database and Cochrane reviews CENTRAL). The journal Quality and Safety in Healthcare (QSHC) was hand searched. Methodological quality was assessed.

Results: Initially, 323 titles were found. Screening of titles and abstracts and full texts resulted in nine articles meeting the inclusion criteria. The methodological quality of the studies was generally low. The innovations included different types of practices. Fifteen different team characteristics were labeled according to six features of successful teams.

Twenty-one different team-directed strategies were identified and inductively categorized.

Conclusion: Few studies and little evidence were found for the relevance of team characteristics and team directed strategies in the implementation of nursing innovations. Feedback was most frequently used as a strategy. Leadership could be labeled as a team characteristic as well as a team directed strategy. Further research should be of good methodological quality and focusing on patient outcomes and time and costs invested in strategy delivery. This increases scientific knowledge on nursing implementation strategies focusing on leadership.
\end{abstract}

(c) 2009 Elsevier Ltd. All rights reserved.

\section{What is already known about the topic?}

- Implementation of innovations is a complex and intensive procedure.

- The relevance of team characteristics and team directed strategies in relation to the implementation of innovations in nursing is unclear.

\footnotetext{
* Corresponding author. Tel.: +31 302919039.

E-mail address: g.holleman@levv.nl (G. Holleman).
}

- Team functioning predicts effectiveness.

\section{What this paper adds}

- The level of evidence for the relevance of team characteristics and team directed strategies in relation to the implementation of innovations in nursing is altogether low.

- Fifteen different team characteristics and 21 team directed strategies relevant to successful implementation of innovations in nursing teams were identified. 
- Feedback was most frequently used as a team directed strategy.

- Knowledge to the world of nursing practice and implementation of innovations, by emphasizing the role of leadership and teams.

\section{Background}

Nursing innovations often require a change of nurses' behavior. Attempts to change behavior are likely to be dependent of the functioning of a team. Teams are natural components of nursing units, and the focus of this article. The implementation of innovations often focuses on the intrinsic motivation (Holleman et al., 2006) instead of the extrinsic motivation of teams. Relevant team characteristics and team directed strategies that can affect the successful implementation (Davis and Taylor-Vaisey, 1997) of an innovation are summarized in this article.

For many years, organizational experts concentrated on organizational efficiency designed to maximize productivity. The assumption was that people do not like to work and must therefore be prodded into action by - among other things - financial incentives, close supervision and clear goals to be attained with minimal effort (Taylor, 1923). This view was shaken by the Hawthorne studies of group productivity (Forsyth, 1999) which showed that people did not work harder because of environmental changes, but because they were part of a small group that responded positively and productively to special treatment. The Disney studios with their visionary leader and talented artists have similarly ascribed their success to the dynamics of the group and not individual abilities (Schickel, 1968). Organizational experts in the 1980s recommended using small groups to accomplish productivity goals while today's experts have gone one step further with the recommendation of teams to achieve organizational excellence (Forsyth, 1999). Teams are described as two or more people working together on specific goal through interrelated activity (Franz, 2004). Teams tend to be part of a larger organization, and individual team members contribute specific knowledge, skills and abilities to the group. Links between team processes and the implementation of innovations are hardly delineated, however social interactions and cognitive processes and their influence on individual change are described in the social learning theory (Bandura, 1977) and the stages of change model (Prochaska, 1992). Teams that are prone to implementation of innovation do not guarantee success but do appear to increase effectiveness and team member satisfaction (Taylor, 1923; Borill et al., 2000; Guzzo and Salas, 1995). To create a safe health care system, providers must understand teamwork as a relationship of interdependence (Sherwood et al., 2002). Since most nurses work in teams, special characteristics of teams may contribute to successful implementation of innovations. Innovations imply the development of new behaviors, the stopping of old behaviors or the modification of current behaviors. To influence these behaviors team-directed strategies can be used, including activities aimed at the rearrangement of specific team qualities such as the use of information and/or the use of peer leaders (Grol et al., 2007). Such activities generally require the adoption of a comprehensive approach, taking into account the stage of change (Rogers, 2003) and tailored to the specific setting and group(s) (Grol and Grimshaw, 2003). Insight in relevant team characteristics and team directed strategies involving nursing teams lacks. We searched the literature for evidence to answer the question: Which team related characteristics or teamdirected strategies are effective in improving outcomes for patients?

\section{Methods}

\subsection{Data sources}

The MEDLINE, CINAHL, PsycINFO and ERIC databases and Cochran reviews CENTRAL were searched without limits for date of publication, language or study design. The Quality and Safety in Healthcare (QSHC) journal (2000-2006) and references from a key publication (Gosling et al., 2003) were hand searched. Keywords used for MEDLINE were the Mesh terms (Team OR Care team OR Nursing team OR Multidisciplinary team) AND (Implementation of an innovation OR Strategy OR Procedure). Implementation of an innovation as a MeSH term included implementation, meaning the introduction of an innovation in daily routines demanding effective communication and removal of hindrances (Davis and Taylor-Vaisley, 1997). Similar combinations were used for searches in the other databases.

\subsection{Study inclusion}

The publications had to meet each of the following three criteria for inclusion in the present review: (1) presentation of results of research on teams in healthcare, including nurses; (2) report on team directed strategies or team factors relevant to the introduction of the innovations; (3) description of an actual diffused and implemented innovation including "intended practices". A publication was excluded when the team itself was the innovation (i.e., "Introduction of twenty-four hour care teams"; Townsend, 1994) or the team itself was the implementation strategy, i.e., "The role of a specialist team in implementing continuing health care guidelines in hospitalized patients" (Cockram et al., 1997). Data published in duplicate were included only once.

Three reviewers (GH, EP, TvA) screened all of the title and abstracts independently to assess the relevance and suitability of the study for inclusion in the present review based on the selection criteria. Publications were first selected on title and abstract. When the abstract did not provide sufficient information, the full text was reviewed. All articles that met the inclusion criteria were methodological assessed using the following instruments: the RCT Critical Appraisal Form; QARI Critical Appraisal Instrument for qualitative research (Joanna Briggs Institute, 2004). For non-randomized intervention studies, the Notari Textual Critical Appraisal and the assessment instrument by Saunders et al. (2003) were used. Disagreements were resolved by discussion until consensus was reached. Levels of evidence were based upon the study design. 
Table 1

Characteristics of successful teams by Franz (2004) and Forsyth (1999).

\begin{tabular}{|c|c|}
\hline Team characteristics & Description \\
\hline Communication & $\begin{array}{l}\text { Open communication, including deep listening, supports civilized disagreement and constructive conflict resolution. } \\
\text { Successful teams agree on procedures for decision-making and mutually negotiate work boundaries. Effective teams } \\
\text { openly share information. }\end{array}$ \\
\hline Cohesion & $\begin{array}{l}\text { Teams with strong commitment to the goal and each other share values and beliefs about their purpose and personal } \\
\text { interactions. A unified commitment through a high level of cohesiveness and participation exists. }\end{array}$ \\
\hline Clear purpose & $\begin{array}{l}\text { Team members understand the group goal and how it fits the overall work. They have clear direction and understand } \\
\text { the nature and complexity of their effort. Team members accept the group's purpose and find it meaningful. }\end{array}$ \\
\hline Team member attributes & $\begin{array}{l}\text { Talents, attitudes, beliefs, values, and personalities each member brings to the team greatly affect success. Group dynamics } \\
\text { fuelled by individual differences, status, power, pressure towards uniformity, and willingness to collaborate affects the } \\
\text { team's work. Success often depends on individual readiness to work with others. }\end{array}$ \\
\hline Strong relationships & $\begin{array}{l}\text { Successful teams build and enhance constructive internal and external relationships in meeting their goals. } \\
\text { This requires collaboration across boundaries and interdependence for completing tasks. }\end{array}$ \\
\hline Trust and confidence & $\begin{array}{l}\text { A high level of trust results in enhanced personal and group confidence. These groups operate informally and } \\
\text { provide psychological safety for their members. Groups with strong trust and confidence support risk taking. }\end{array}$ \\
\hline Accountability & $\begin{array}{l}\text { Results, accountability, and high standards of excellence drive successful teams. Members share responsibility } \\
\text { for outcomes, and everyone contributes. }\end{array}$ \\
\hline Leadership & $\begin{array}{l}\text { Successful work teams thrive when leaders create environments that nurture creativity, accomplishments, and } \\
\text { relationships. These leaders are supportive, principled, and serve as coaches and facilitators. They lead group processes } \\
\text { that balance task with relationship building and enhance the group's capacity for change. }\end{array}$ \\
\hline $\begin{array}{l}\text { Clear, enticing roles and } \\
\text { responsibilities }\end{array}$ & $\begin{array}{l}\text { Members of successful teams understand what needs accomplishing, and they enjoy working together. They realize } \\
\text { individual efforts contribute to the larger organization in a meaningful way. }\end{array}$ \\
\hline Physical factors & $\begin{array}{l}\text { Successful teams depend on size, material resources, and physical operating environments. The influence of these factors } \\
\text { often relates to the nature of the task. }\end{array}$ \\
\hline
\end{tabular}

\subsection{Data extraction}

A data extraction form was developed and pilot-tested with three of the nine selected studies and refined accordingly. Three reviewers performed the data extraction. The data extraction form addressed the innovation, the study population, team-characteristics, team-related or team-directed strategy (minimal criteria), outcomes (type of outcome: patient outcome, health worker outcome) and measurement tools (type, psychometrics). The team characteristics were deductively categorized according to group dynamics literature of Forsyth (1999) and Franz (2004) describing 10 characteristics of successful teams (Table 1). Two researchers independently inductively categorized the team-directed strategies focusing on information, monitoring, feedback and leadership.

\section{Results}

The initial search strategy revealed 323 hits, including duplicates. Subsequent selection based on the title and abstract of the publication yielded 113 potentially relevant abstracts. Inspection of the abstracts yielded 35 possibly relevant publications. Moreover, 13 publications were selected based on their full texts (see Table 2). Subtracting the duplicates and checking for inclusion and exclusion criteria once more resulted in nine studies meeting the inclusion and quality criteria.

\subsection{Description of the studies}

Seven publications addressed multidisciplinary teamwork; two addressed interdisciplinary teamwork (Table 3 ). Six studies related to teams in hospitals and three to teams

Table 2

Search results for studies of team-related characteristics and team-directed strategies.

\begin{tabular}{|c|c|c|c|}
\hline & Years searched & Number of hits based on search strategy & Number of hits based on full text \\
\hline \multicolumn{4}{|l|}{ Searches } \\
\hline MEDLINE & 1989-2006 & 83 & 4 \\
\hline CINAHL & 1982-2006 & 160 & 4 \\
\hline PsycINFO & 1971-2006 & 24 & 2 \\
\hline ERIC database & $1982-2006$ & 29 & 0 \\
\hline References hits & & 12 & 2 \\
\hline Hand searched QSHC & 2000-2006 & 15 & 1 \\
\hline \multirow[t]{6}{*}{ Cochrane: systematic reviews } & & 0 & 0 \\
\hline & \multicolumn{2}{|c|}{ Total for all searches 323} & 13 \\
\hline & \multicolumn{2}{|l|}{ Duplicates } & 1 \\
\hline & \multicolumn{2}{|c|}{ Two publications on one study } & 1 \\
\hline & \multicolumn{2}{|c|}{$\begin{array}{l}\text { Publications involving team itself as innovation or implementation } \\
\text { strategy = reden exclusive }\end{array}$} & 2 \\
\hline & \multicolumn{2}{|l|}{ Total } & 9 \\
\hline
\end{tabular}


Table 3

Overview selected studies.

\begin{tabular}{|c|c|c|c|c|c|c|}
\hline \multirow[t]{2}{*}{ Author (year) } & \multirow[t]{2}{*}{ Research question (abbreviated) } & \multirow[t]{2}{*}{ Design } & \multirow[t]{2}{*}{ Innovation } & \multirow[t]{2}{*}{ Team sample } & \multicolumn{2}{|l|}{ Results found } \\
\hline & & & & & Team characteristics & Team-directed strategies \\
\hline $\begin{array}{l}\text { Chan et al. } \\
\text { (2001) }\end{array}$ & $\begin{array}{l}\text { How to design and implement a } \\
\text { MDT-driven extubation protocol } \\
\text { with a positive and safe impact } \\
\text { on the patient and the MD? }\end{array}$ & $\begin{array}{l}\text { Controlled clinical } \\
\text { trial }\end{array}$ & Protocol & $\begin{array}{l}\text { Intensive Care Unit } \\
\text { in an academic } \\
\text { university-affiliated } \\
\text { hospital }\end{array}$ & Not defined & $\begin{array}{l}\text { Ongoing re-evaluation and } \\
\text { modification of MD input }\end{array}$ \\
\hline $\begin{array}{l}\text { Cooper and } \\
\text { Hewison } \\
(2002)\end{array}$ & $\begin{array}{l}\text { Which intervention strategies } \\
\text { influence successful } \\
\text { implementation of audit in } \\
\text { palliative care? }\end{array}$ & Action research & Clinical audit & $\begin{array}{l}\text { Palliative home care } \\
\text { and home support } \\
\text { team, day unit } \\
\text { staff }(n=10)\end{array}$ & Not defined & $\begin{array}{l}\text { Analysis of previous } \\
\text { implementation projects } \\
\text { Bottom-up approach } \\
\text { Collaboration } \\
\text { External facilitator } \\
\text { Continuous monitoring } \\
\text { Regular feedback }\end{array}$ \\
\hline $\begin{array}{l}\text { Edmondson } \\
\quad(2003)\end{array}$ & $\begin{array}{l}\text { How do leaders of action } \\
\text { teams promote learning in } \\
\text { interdisciplinary teams? }\end{array}$ & $\begin{array}{l}\text { Multiple case study } \\
\text { pretest-post-test } \\
\text { design }\end{array}$ & $\begin{array}{l}\text { New technology } \\
\text { for cardiac } \\
\text { surgery }\end{array}$ & $\begin{array}{l}\text { Cardiac surgery } \\
\text { teams }(n=16)\end{array}$ & $\begin{array}{l}\text { Team stability } \\
\text { Team preparation } \\
\text { Communication } \\
\text { Differences in expertise } \\
\text { Boundary spanning } \\
\text { Ease of speaking up } \\
\text { Psychological safety } \\
\text { Supportive organizational context }\end{array}$ & Not defined \\
\hline $\begin{array}{l}\text { Galvin et al. } \\
\text { (1999) }\end{array}$ & $\begin{array}{l}\text { What are key areas for } \\
\text { change and what are } \\
\text { additional nursing skills } \\
\text { for teams? }\end{array}$ & Action research & $\begin{array}{l}\text { User initiated } \\
\text { service }\end{array}$ & $\begin{array}{l}\text { Primary health care } \\
\text { nursing team }(n=7)\end{array}$ & Not defined & $\begin{array}{l}\text { Regular team meetings } \\
\text { Task analysis } \\
\text { Team workshops } \\
\text { Reflective diaries }\end{array}$ \\
\hline $\begin{array}{l}\text { Gibbon et al. } \\
(2002)\end{array}$ & $\begin{array}{l}\text { Do team-coordinated } \\
\text { approaches to stroke care } \\
\text { and rehabilitation improve } \\
\text { staff attitudes to working } \\
\text { in a team? }\end{array}$ & $\begin{array}{l}\text { Pretest-post-test } \\
\text { design }\end{array}$ & $\begin{array}{l}\text { Integrated care } \\
\text { pathway and } \\
\text { unified team } \\
\text { notes }\end{array}$ & $\begin{array}{l}\text { Stroke units }(n=4) \\
\text { during baseline and } \\
\text { post-intervention, } \\
\text { patients }(n=122)\end{array}$ & $\begin{array}{l}\text { Jealousy } \\
\text { Perceived loss of autonomy } \\
\text { Threat to professional status } \\
\text { Vision } \\
\text { Participative safety } \\
\text { Task orientation } \\
\text { Support for innovation }\end{array}$ & Not defined \\
\hline
\end{tabular}


Table 3 (Continued)

\begin{tabular}{|c|c|c|c|c|c|c|}
\hline \multirow[t]{2}{*}{ Author (year) } & \multirow[t]{2}{*}{ Research question (abbreviated) } & \multirow[t]{2}{*}{ Design } & \multirow[t]{2}{*}{ Innovation } & \multirow[t]{2}{*}{ Team sample } & \multicolumn{2}{|l|}{ Results found } \\
\hline & & & & & Team characteristics & Team-directed strategies \\
\hline \multirow[t]{4}{*}{$\begin{array}{l}\text { Gosling et al. } \\
\text { (2003) }\end{array}$} & $\begin{array}{l}\text { What is the association between } \\
\text { clinical team functioning and the } \\
\text { adoption and diffusion of an } \\
\text { online evidence retrieval system? }\end{array}$ & $\begin{array}{l}\text { Cross-sectional } \\
\text { observational } \\
\text { study }\end{array}$ & $\begin{array}{l}\text { Evidence retrieval } \\
\text { system }\end{array}$ & $\begin{array}{l}\text { Teams }(n=18) \\
\text { clinicians }(n=180)\end{array}$ & Vision & Not defined \\
\hline & & & & & Participative safety & \\
\hline & & & & & Task orientation & \\
\hline & & & & & Support for innovation & \\
\hline \multirow[t]{3}{*}{ Hobbs (2004) } & $\begin{array}{l}\text { What are the effects of structured } \\
\text { program to reduce pressure ulcers? }\end{array}$ & $\begin{array}{l}\text { Pretest-post-test } \\
\text { design }\end{array}$ & $\begin{array}{l}\text { Turn-team nursing } \\
\text { program }\end{array}$ & Geriatric nurses & Not defined & $\begin{array}{l}\text { 8-h training program Team } \\
\text { approach with identified } \\
\text { responsibilities }\end{array}$ \\
\hline & & & & & & $\begin{array}{l}\text { Bi-weekly meetings of staff } \\
\text { with management }\end{array}$ \\
\hline & & & & & & Monitoring by senior nursing staff \\
\hline \multirow{5}{*}{$\begin{array}{l}\text { Rubenstein et al. } \\
\text { (2002) }\end{array}$} & & & Quality improvement & Primary care & Expert team leadership & Not defined \\
\hline & $\begin{array}{l}\text { improvement teams and their } \\
\text { environments in depression care } \\
\text { improvement programs? }\end{array}$ & $\begin{array}{l}\text { formative } \\
\text { evaluation }\end{array}$ & program & practices $(n=6)$ & & \\
\hline & & & & & Support from management & \\
\hline & & & & & Support from specialist & \\
\hline & & & & & Clear purpose & \\
\hline \multirow{9}{*}{$\begin{array}{l}\text { Victor and } \\
\text { Persoon (1994) }\end{array}$} & How to implement kangaroo & Case study & New care (kangaroo) & Intensive Care & Mutual respect & Continual monitoring \\
\hline & $\begin{array}{l}\text { care in Intensive Care Unit: a } \\
\text { parent health-care team approach. }\end{array}$ & & & & & and education \\
\hline & & & & & Clearly articulated support & Use of parental input \\
\hline & & & & & Vision & Use of the "What if" game \\
\hline & & & & & & Discussion meetings \\
\hline & & & & & & Information sessions \\
\hline & & & & & & Review of articles \\
\hline & & & & & & Use of peer leaders \\
\hline & & & & & & Accent on positive outcomes \\
\hline
\end{tabular}


in primary care practices. The quality of eight studies was low due to weak design such as a case study (Rubenstein et al., 2002). Only one study had a moderate to high level of evidence (Chan et al., 2001), permitting evidence based results. In this CCT study, the team's competence with respect to 'the design and implementation of a multidisciplinary team-driven extubation protocol with a positive impact on the patient' was described (Chan et al., 2001). However, no statistically significant results were found. Five of the nine studies described team characteristics and seven of the nine studies described team directed strategies.

\subsection{Types of innovations}

The innovations of the nine studies included, the implementation of a clinical audit in a palliative care setting (Cooper and Hewison, 2002); an user-led service in a primary care setting (Galvin et al., 1999); a quality improvement program (Rubenstein et al., 2002); a multidisciplinary team driven extubation protocol in an Intensive Care Unit (Chan et al., 2001); kangaroo care in an ICU (Victor and Persoon, 1994); a new technology for cardiac surgery (Edmondson, 2003); a turn-team program to reduce pressure ulcer prevalence in a geriatric hospital (Hobbs, 2004); integrated care pathway and unified team notes (Gibbon et al., 2002); and the implementation of an evidence retrieval system (Gosling et al., 2003) (Table 3).

The innovations all involved "proposed practices," which meant that new behaviors had to be developed, old behaviors had to be stopped or current behaviors had to be modified with team functioning as the focus of the efforts. Five of the nine studies described team characteristics and seven of the nine studies described team directed strategies, which meant that three studies described team directed characteristics as well as team directed strategies.

\subsection{Team characteristics}

Team characteristics were described in five studies (Gosling et al., 2003; Rubenstein et al., 2002; Victor and Persoon, 1994; Edmondson, 2003; Gibbon et al., 2002). Fifteen different team characteristics associated with implementation of innovations were identified in five different publications, using both quantitative (controlled clinical trail (CCT), pretest-post-test design (PPT), crosssectional, case study) and qualitative designs (action research, comparative formative evaluation). These characteristics can be categorized in 6 of the 10 features related to successful teams as described by Forsyth (1999) and Franz (2004) (Table 1). Team characteristics relating to trust and confidence, clear purpose, and leadership dominate (Tables 4 and 5).

\subsubsection{Communication}

One study showed that communication is optimal in small teams ( $<15$ members) and contributes to learning, when implementing a new technique or procedure (Edmondson, 2003).

\subsubsection{Clear purpose}

A clear purpose (vision) is described as conducive to teams associated with implementation of innovations (Gosling et al., 2003; Rubenstein et al., 2002; Victor and Persoon, 1994; Gibbon et al., 2002). Team objectives are shared and agreed upon before implementing an integrated care pathway or an evidence retrieval system (Gosling et al., 2003; Gibbon et al., 2002). Team goal setting requires leadership at the outset to establish a clear, shared and attainable vision (Rubenstein et al., 2002; Victor and Persoon, 1994). Task orientation and speaking up in the service of learning directly contribute to an effective and innovative team climate (Gosling et al., 2003; Gibbon et al., 2002).

Table 4

Overview of team characteristics associated with implementation of innovation.

\begin{tabular}{|c|c|c|c|c|c|}
\hline Communication & Clear purpose & $\begin{array}{l}\text { Team member } \\
\text { attributes }\end{array}$ & Trust and confidence & Leadership & $\begin{array}{l}\text { Roles and } \\
\text { responsibilities }\end{array}$ \\
\hline \multirow[t]{4}{*}{$\begin{array}{l}\text { Communication } \\
\text { (Edmondson, } \\
\text { 2003) }\end{array}$} & $\begin{array}{l}\text { Vision (Gosling et al., } \\
\text { 2003; Rubenstein } \\
\text { et al., 2002; Victor and } \\
\text { Persoon, 1994; Gibbon } \\
\text { et al., 2002) }\end{array}$ & $\begin{array}{l}\text { Staffing level expertise } \\
\text { (Edmondson, 2003) }\end{array}$ & $\begin{array}{l}\text { Jealousy (Gibbon et al., } \\
\text { 2002) }\end{array}$ & $\begin{array}{l}\text { Expert team leadership } \\
\text { (Rubenstein et al., 2002) }\end{array}$ & $\begin{array}{l}\text { Boundary spanning } \\
\text { (Edmondson, 2003) }\end{array}$ \\
\hline & $\begin{array}{l}\text { Task orientation } \\
\text { (Gibbon et al., 2002; } \\
\text { Gosling et al., 2003) }\end{array}$ & & $\begin{array}{l}\text { Ignorance (Gibbon et al., } \\
\text { 2002) }\end{array}$ & $\begin{array}{l}\text { Management support } \\
\text { (Rubenstein et al., 2002; } \\
\text { Edmondson, 2003; Gibbon } \\
\text { et al., 2002; Gosling } \\
\text { et al., 2003; Victor and } \\
\text { Persoon, 1994) }\end{array}$ & $\begin{array}{l}\text { Perceived loss of } \\
\text { autonomy } \\
\text { (Gibbon et al., 2002) }\end{array}$ \\
\hline & & & $\begin{array}{l}\text { Stability (Edmondson, } \\
\text { 2003) }\end{array}$ & & $\begin{array}{l}\text { Threat to professiona } \\
\text { status (Gibbon et } \\
\text { al., 2002) }\end{array}$ \\
\hline & & & $\begin{array}{l}\text { Safety (Edmondson, 2003; } \\
\text { Gibbon et al., 2002; } \\
\text { Gosling et al., 2003) } \\
\text { Mutual respect } \\
\text { (Victor and Persoon, } \\
\text { 1994) } \\
\text { Team preparation } \\
\text { (Edmondson, 2003) }\end{array}$ & & \\
\hline
\end{tabular}


Table 5

Overview of team-directed strategies inductively grouped to five different categories.

\begin{tabular}{|c|c|c|c|c|}
\hline Education & Monitoring & Feedback & Leadership & Other \\
\hline $\begin{array}{l}\text { Team workshop } \\
\text { (Galvin et al., 1999) }\end{array}$ & $\begin{array}{l}\text { Monitoring (Cooper } \\
\text { and Hewison, 2002; } \\
\text { Hobbs, 2004) }\end{array}$ & $\begin{array}{l}\text { Ongoing re-evaluation and } \\
\text { modification (Chan et al., } \\
\text { 2001) }\end{array}$ & $\begin{array}{l}\text { Leadership downplaying } \\
\text { the power imbalance } \\
\text { (Gosling et al., 2003) }\end{array}$ & $\begin{array}{l}\text { Action research } \\
\text { (Rubenstein et al., 2002) }\end{array}$ \\
\hline $\begin{array}{l}\text { Information session } \\
\text { (Victor and Persoon, } \\
\text { 1994) }\end{array}$ & $\begin{array}{l}\text { Continual monitoring } \\
\text { and education (Victor } \\
\text { and Persoon, 1994) }\end{array}$ & $\begin{array}{l}\text { Feedback (Cooper and } \\
\text { Hewison, 2002) }\end{array}$ & $\begin{array}{l}\text { Coached leadership } \\
\text { (Chan et al., 2001; } \\
\text { Gosling et al., 2003) }\end{array}$ & $\begin{array}{l}\text { Audit process } \\
\text { (Victor and Persoon, 1994) }\end{array}$ \\
\hline $\begin{array}{l}\text { Training program } \\
\quad \text { (Hobbs, 2004) }\end{array}$ & & $\begin{array}{l}\text { Reflective diaries } \\
\text { (Galvin et al., 1999) } \\
\text { Task analysis } \\
\text { (Galvin et al., 1999) } \\
\text { "What if ...?" game } \\
\text { (Victor and Persoon, 1994) } \\
\text { Review of articles } \\
\text { (Victor and Persoon, 1994) } \\
\text { Emphasizing positive } \\
\text { outcomes (Victor and } \\
\text { Persoon, 1994) } \\
\text { Discussion meetings } \\
\text { (Victor and Persoon, 1994) } \\
\text { Focus group interviews } \\
\text { (Victor and Persoon, 1994) } \\
\text { Biweekly reflection meetings } \\
\text { (Hobbs, 2004) }\end{array}$ & $\begin{array}{l}\text { Use of peer leaders } \\
\text { (Victor and Persoon, 1994) } \\
\text { Use of input from family } \\
\text { (Victor and Persoon, 1994) }\end{array}$ & \\
\hline
\end{tabular}

\subsubsection{Team member attributes}

One study (Edmondson, 2003) described that a right mix of experience and skills is needed to establish a team identity in fast-paced action contexts as an ICU, emergency room or operating theatre when implementing a new technology for cardiac surgery.

\subsubsection{Trust and confidence}

Team characteristics related to levels of support and challenges are described in four studies (Gosling et al., 2003; Victor and Persoon, 1994; Edmondson, 2003; Gibbon et al., 2002). Psychologically safe feelings in the team are conducive to easily propose new and improved ways of doing things and participate in decision-making processes. The extent to which team members feel free to communicate observations, questions and concerns can critically influence team outcomes, especially members of operating room teams who must act in often uncertain and fast-paced situations (Edmondson, 2003).

\subsubsection{Leadership}

Five studies (Gosling et al., 2003; Rubenstein et al., 2002; Victor and Persoon, 1994; Edmondson, 2003; Gibbon et al., 2002) described characteristics relating to leadership. From a case study on implementing 'kangaroo care', Victor and Persoon (1994) concluded that leadership through management support must be clearly articulated and enacted. Perceived lack of support or uncertainty about the intentions of management was described as having disastrous effects on morale and overshadows attempts encouraging effective teamwork.

The Team Climate Inventory (TCI) was used in a prepost and cross-sectional design, addressing the team climate in relation to the implementation of an innovation (Gosling et al., 2003; Gibbon et al., 2002). This instrument is a multidimensional measure of team climate focusing on five different factors of team success including vision, support for innovation, task orientation and participative safety with the subscale 'information sharing and interaction frequency' and the subscale 'safety and influence' (Anderson and West, 1998; Ouwens et al., 2008).

Leadership is mainly described in the context of management support and once described in the context of expert team leadership (Rubenstein et al., 2002).

\subsubsection{Roles and responsibilities}

Two studies (Edmondson, 2003; Gibbon et al., 2002) described features related to roles and responsibilities in teams. Clearly defined roles, a clear understanding of one's own role and the roles of colleagues positively affect team functioning in the domain of stroke care (Gibbon et al., 2002). Additionally, clearly defined roles prevent perceived losses of autonomy and decrease perceived threats to one's professional status or boundary spanning (Edmondson, 2003; Gibbon et al., 2002).

\subsection{Team-directed strategies}

Twenty-one different team-directed strategies were identified in seven studies using both quantitative and qualitative designs (Gosling et al., 2003; Chan et al., 2001; Cooper and Hewison, 2002; Galvin et al., 1999; Rubenstein et al., 2002; Victor and Persoon, 1994; Hobbs, 2004). All strategies were inductively categorized focusing on education, monitoring, feedback, leadership and 'other'. Integrated strategies were used most often, feedback dominated. Only one study described team characteristics as well as and team directed strategies (Victor and Persoon, 1994), however no relation was described.

\subsection{Education}

Three studies (Galvin et al., 1999; Victor and Persoon, 1994; Hobbs, 2004) described strategies directly asso- 
ciated with education. In one study (Victor and Persoon, 1994) workshops were used examining findings from data, exploring key areas of patient need and ideas about how practice could be changed in a primary health care nursing team. Information sessions were used in one study (Victor and Persoon, 1994) for patients and nursing team implementing kangaroo care. A training program was given in combination with biweekly reflection meetings using a pre-post design informing the team about a more holistic approach stressing the importance of systematic, preventive care in order to reduce the incidence of pressure ulcers (Hobbs, 2004).

\subsection{Monitoring}

Three studies (Cooper and Hewison, 2002; Victor and Persoon, 1994; Hobbs, 2004) used monitoring as a team directed strategy. One study (Victor and Persoon, 1994) described a case study with integrated team directed strategies implementing kangaroo care. Continual monitoring was used to persuade nursing staff to share decisions about parental participation. A turn team program reducing the incidence of pressure ulcers (Hobbs, 2004) used integrated team directed strategies including monitoring of patients referrals to the enterosotomal nurse, the average length of stay, musculoskeletal injuries among staff and incidence of nosocomial infections.

\subsection{Feedback}

Five studies (Chan et al., 2001; Cooper and Hewison, 2002; Galvin et al., 1999; Victor and Persoon, 1994; Hobbs, 2004) described feedback related activities as team directed strategies. In one study (Galvin et al., 1999) task analysis and reflective diaries were integrated persuading a primary health care team to change to a new method of working. Each member of the team record a typical working week highlighting key tasks and responsibilities that identified the practice boundaries and specific specialist and generic areas of practice. A summary of key tasks made the types of activities performed by different nurses more apparent. In addition, focus group interviews with patients evaluated the performance of the primary health care team. The implementation of kangaroo care (Victor and Persoon, 1994) combined different team directed strategies as well. Nurses were convinced of the value of the innovation by emphasizing the positive outcomes and playing the "What if ...?" game. This game helped monitoring the most important infant parameters during kangaroo care and evaluating infant responses. Reviews of articles were discussed in meetings stressing positive outcomes for patients, parents and nurses. One study (Chan et al., 2001) stressed the importance of ongoing re-evaluation and modification of a protocol. Prompt and relevant feedback on the progress of the implementation of an audit in palliative care (Cooper and Hewison, 2002) and biweekly meetings reflecting on the progress of the implementation of the turn-team (Hobbs, 2004) were positively associated with successful implementation of the innovations.

\subsection{Leadership}

Leadership as a team directed strategy was described in three studies (Gosling et al., 2003; Chan et al., 2001; Victor and Persoon, 1994). Leadership is used downplaying the power imbalance through coached leadership (Gosling et al., 2003). Attention for psychological safety, the presentation of a clear rationale for change and coaching by team leaders, enhance the durability of an innovation (Victor and Persoon, 1994). An environment that ensures psychological safety gains respect for the various ways in which professionals communicate and speak up. Motivation and coaching by the team leader encourages team members to speak openly within the team and communicate with others in the organization about ongoing changes. The presentation of clear rationales by the team leader helps individuals to focus. Coaching influences individual performance and can thus greatly affect an organization's capacity to execute. These behaviors constitute part of a multifaceted team learning process that clearly enables successful implementation (Chan et al., 2001).

\subsection{Other}

One study (Cooper and Hewison, 2002) used the combination of an action research approach and audit cycle to facilitate a change in palliative care. Both processes have similarities as they are cyclical in nature and include the elements of planning, review and feedback.

\section{Discussion and conclusion}

Introduction of innovation and change in health care is difficult and many programs for improving care are, at best, only partly successful. Our review departed from the presupposition that the team functioning is relevant to the quality of patient care. Insight in relevant team characteristics and in influencing team functioning through team directed interventions is lacking. Since teams are natural components of nursing units, we decided to search the literature for evidence. Various descriptions of team characteristics and approaches towards change were found and described, but due to weak research methods, the relevance of team characteristics and team directed strategies was not clearly demonstrated.

Our literature review yielded few studies (9) and little evidence. We expected to find team characteristics and related single or combined strategies described together in one study, however only one study described relevant team characteristics and matching team directed strategies.

Leadership is described as a team characteristic as well as a team directed strategy. This is in line with successful team characteristics as described by Franz (2004) and Forsyth (1999). Furthermore, this finding matches the advice of the Institute for Health Improvement and other worldwide safety related institutes. These institutes propose leadership in combination with small steps of change and monitoring as a valuable team directed change strategy. 
Action research was twice reported as a strategy to improve the functioning of a team during the implementation of an innovation. The involvement of a researcher in this process could come with difficulties. Some authors argue that the researcher can serve as a facilitator or catalyst and thus help nurses develop their own analyses, assist with the implementation of an innovation and ultimately serve as a resource person. Others find the outsider role to be quite difficult, particularly when the team wants to adopt a bottom-up, practice-based approach and thus have someone coordinate the innovation endeavor from within. The role and responsibilities of the researcher may also blur under such conditions and possibly lead to outcomes, which are questionable.

More research on team characteristics and team directed strategies is needed. This research should include studies focusing on patient outcomes and time and costs invested in strategy delivery. This will add to the further development of nursing implementation science and evidence based nursing practice. Research could especially focus on leadership and the ability of leaders to put ideas into practice. Health care providers in general and nurses in particular need explicit suggestions on effective communication and teamwork rather than learning by trial and error, which can instill unintended values, attitudes, and behaviors.

\section{Conflict of interest}

No conflict of interest to be declared.

\section{Acknowledgements}

Contribution: TvA and EP participated in the selection of the publications to be included in this review. TvA also participated in the design and coordination of the study. TvA, JM and EP helped draft the present manuscript. In addition, all authors read and approved the final manuscript.

\section{References}

Anderson, N., West, M., 1998. Measuring climate for work group innovation: development and validation of the team climate inventory. J. Org. Behav. 19, 235-258.

Bandura, A., 1977. Social Learning Theory. Pretence Hall, Englewood Cliffs, NJ.

Borill, C., West, M., Shapiro, D., Rees, A., 2000. Team working and effectiveness health care. Health Care Manage. 6 (8), 364-371.

Chan, P.K.O., Fischer, S., Stewart, T.E., Hallett, D.C., Hynes-Gay, P., Lapinsky, S.E., MacDonald, R., Meta, S., 2001. Practising evidencebased medicine: the design and implementation of a multidisciplinary team-driven extubation protocol. Crit. Care Med. 5, 349-354.

Cockram, A., Gibb, R., Kalra, L., 1997. The role of a specialist team in implementing continuing health care guidelines in hospitalised patients. Age Ageing 26 (May(3)), 211-216.
Cooper, J., Hewison, A., 2002. Implementing audit in palliative care: an action research approach. J. Adv. Nurs. 39 (4), 360-369.

Davis, D.A., Taylor-Vaisey, A., 1997. Translating guidelines into practice. A systematic review of theoretic concepts, practical experience and research evidence in the adoption of clinical guidelines. CMAJ 157 (4), 408-416.

Davis, D.A., Taylor-Vaisley, A., 1997. Translating guidelines into practice. A systematic review of theoretic concepts, practical experience and research evidence in the adoption of clinical practice guidelines. CMAJ 157 (4), 408-416.

Edmondson, A.C., 2003. Speaking up in the operating room: how team leaders promote learning in interdisciplinary action teams. J. Manage. Stud. 40, 6.

Forsyth, D., 1999. Group Dynamics, 3rd ed. Brooks/Cole Wadsworth, New York.

Franz, N.K., 2004. Self directed teams: the antidote for 'heroic suicide'. JofE 42 (2).

Galvin, K., Andrews, C., Jackson, D., Cheesman, S., Fudge, T., Ferris, R., Graham, I., 1999. Investigating and implementing change within the primary health care nursing team. J. Adv. Nurs. 30 (1), 238-247.

Gibbon, B., Watkins, C., Barer, D., Waters, K., Davies, S., Lightbody, L., Leathley, M., 2002. Can staff attitudes to team working in stroke care be improved? J. Adv. Nurs. 40 (1), 105-111.

Gosling, A.S., Westbrook, D.J.I., Braithwaite, J., 2003. Clinical team functioning and IT innovation: a study of the diffusion of a point-of care online evidence system. J. Am. Med. Inform. Assoc. 10, 244-251.

Grol, R., Grimshaw, J., 2003. From best evidence to best practice: effective implementation of change in patients' care. Lancet 11, 1225-1230.

Grol, R.P., Bosch, M.C., Hulscher, M.E., Eccles, M.P., Wensing, M., 2007. Planning and studying improvement in patient care: the use of theoretical perspectives. Milbank Q 85 (1), 93-138.

Guzzo, R.A., Salas, E., 1995. Team effectiveness and decision making in organizations. Strategic Manag. J. (23), 275-284.

Hobbs, B.K., 2004. Reducing the incidence of pressure ulcers. J. Gerontol. Nurs. 46-51.

Holleman, G., Eliens, A., van Vliet, M., van Achterberg, T., 2006. Promotion of evidence-based practice by professional nursing associations: literature review. J. Adv. Nurs. 53 (6), 702-709.

Joanna Briggs Institute: RCT Critical Appraisal Form; QARI Critical Appraisal Instrument for Qualitative Research and Notari Textual Critical Appraisal Instrument from Comprehensive Systematic Review Training Program 2004. The Joanna Briggs Institute Adelaide South Australia.

Ouwens, M., Hulscher, M., Akkermans, R., Hermens, R., Grol, R., Wollersheim, H., 2008. The Team Climate Inventory: application in hospital teams and methodological considerations. Quality and Safety in Health Care 17, 275-280.

Prochaska, J., DiClemente, C., Norcross, J., 1992. In search of how people change. Applications to addictive behaviours. Am. Psychol. 47 (9), $102-114$.

Rogers, E.M., 2003. Diffusion of Innovation, 5th ed. Free Press, New York.

Rubenstein, L.V., Parker, L.E., Meredith, L.S., Altschuler, A., de Phillis, E. Hernandez, J., Gordon, N.P., 2002. Understanding team-based quality improvement for depression in primary care. Health Serv. Res. 37 (4), 1009-1029.

Saunders, L.D., Soomro, G.M., Buckingham, J., Jamtveldt, G., Raina, P., 2003. Assessing the methodological quality of non-randomised intervention studies. West J. Nurs. Res. 25, 223-237.

Schickel, R., 1968. The Disney Version: The Life, Times, Art and Commerce of Walt.

Sherwood, G., Thomas, E., Bennett, D.S., Lewis, P., 2002. A teamwork model to promote patient safety in critical care. Crit. Care Nurs. Clin. North Am. 14 (4), 333-340.

Taylor, F.W., 1923. The Principles of Scientific Management. Harper, New York.

Townsend, M.B., 1994. Twenty-four hour care teams. Nurs. Manage. 25 (6), 62-64.

Victor, L., Persoon, J., 1994. Implementation of kangaroo care. Crit. Care Nurs. Clin. North Am. 4, 891-895. 